\title{
Status of High-efficiency Motor Technology and MEPS
}

\author{
Kibong Jang ${ }^{\dagger}$
}

\begin{abstract}
Minimum Energy Performance Standard(MEPS) has been adapted in Korea since 2008. The efficiency standard of variable speed motors is scheduled for publication shortly. In this paper, author reviews the technical trends associated with a high efficient electric motors by reference to research papers, and reviews the research direction to prepare for IE5. This paper provides an overview of high efficiency motors. Various applications have been covered.
\end{abstract}

Keywords: MEPS, Premium, Super premium, Ultra SUPER Premium, IE4, IE5, High efficiency

\section{Introduction}

More than $60 \%$ of the electricity produced is consumed by the electric motor, most consumed by the induction motor. Therefore, many countries regulate the energy efficiency of the induction motor to reduce the electric energy consumption. Table 1 shows the countries which currently require the industry to meet the energy efficiency requirements. The IEC has developed an internationally applicable testing standard for electric motors, and South Korea is currently at application of IE3 grade for the motor efficiency. Recent advances in technology and environmental regulations have been pushing the ultra

Table 1. Status of Minimum Energy Performance Standard

\begin{tabular}{|c|c|c|}
\hline & MEPS & Outlook \\
\hline Korea & $\begin{array}{l}\text { First performed in } 2008 \\
\text { IE2 applicable to } 0.75 \sim 200 \mathrm{~kW} \text { class } \\
201537 \sim 200 \mathrm{~kW} \text { class IE3 applies }\end{array}$ & $\begin{array}{l}201837 \mathrm{~kW} \text { or less } \\
\text { expected to apply to } \\
\text { IE3 }\end{array}$ \\
\hline Australia & $\begin{array}{l}\text { First performed in } 2001 \\
\text { Enforcement revised } 2006 \\
\text { IE2 rated or higher mandatory }\end{array}$ & $\begin{array}{l}\text { IE3 rating change over } \\
\text { plan }\end{array}$ \\
\hline Brazil & $\begin{array}{l}\text { First performed in } 2009 \\
\text { IE2 rated or higher }\end{array}$ & 2017 planned revision \\
\hline China & IE2 applied in less than $2.2 \mathrm{~kW} 2011$ & $\begin{array}{l}2016 \text { expected to } \\
\text { apply to IE3 }\end{array}$ \\
\hline Canada & $\begin{array}{l}\text { IE2 rated or higher } \\
\text { Since } 2012 \text {, some of the } 1 \sim 200 \mathrm{hp} \\
\text { class IE3 applies }\end{array}$ & Not yet scheduled \\
\hline Turkey & Not yet & $\begin{array}{c}\text { Since } 2017 \mathrm{IE} 3 \\
\text { applies to } 0.75 \mathrm{~kW} \sim \\
375 \mathrm{~kW} \text { scheduled }\end{array}$ \\
\hline $\mathrm{EU}$ & $\begin{array}{l}2011 \text { apply IE2 } \\
2015 \text { apply to IE3(more than } 7.5 \mathrm{~kW} \text { ) }\end{array}$ & $\begin{array}{l}\text { IE3 going to apply to } \\
\text { large since } 2017 \\
\end{array}$ \\
\hline USA & $\begin{array}{l}\text { Since } 2010 \text {, apply IE2 } \\
\text { IE3 applies to models below } 200 \mathrm{hp}\end{array}$ & $\begin{array}{l}\text { IE3 going to apply } \\
\text { more than } 500 \mathrm{hp} \\
\text { model }\end{array}$ \\
\hline Mexico & $\begin{array}{l}\text { Since } 2010 \text {, more than } 375 \mathrm{~kW} \text { IE2 } \\
\text { application }\end{array}$ & $\begin{array}{c}\text { Expected to follow the } \\
\text { US }\end{array}$ \\
\hline Japan & Since 2015 IE3 applies & Not yet scheduled \\
\hline $\begin{array}{l}\text { Saudi } \\
\text { Arabia }\end{array}$ & Since 2015 IE2 application & 2017 planned IE3 \\
\hline
\end{tabular}

$\dagger$ Corresponding Author: Dept. of Electrical Engineering, Changwon National University, Korea. (kbjang@changwon.ac.kr) Received: September 22, 2016; Accepted: December 12, 2016 high-efficiency electric motors gradually into the market. Motor market is expected to grow to 5,160 units in 2019 from the 4,580 units in 2014. As shown in Fig. 1, with the IE3 motor market expected to grow significantly. [1] With the current market of high-efficiency motors growing rapidly, some motor manufacturers are already producing in IE4 motor grade, and many researches have been conducted for the motors with IE5 grade. The purpose of this paper is to review important domestic and global technologies and standards related to the electric motor efficiency to prepare for the forthcoming IE5 market, and provide a thorough survey of both commercial products as well as what is available in literature in terms of high efficiency motors.

\section{Outlook for High-efficiency Motors}

The standards relating to motor efficiency are rapidly being integrated into the IEC standard. Table 2 summarizes the information related to the status of the main rotator efficiency for the IEC standards. [2] Standards for efficiency measuring method of line fed motors (IEC 60034-2-1) and their efficiency codes (IEC 60034-30-1) has already been published and they have become the basis of the lowest efficiency requirement. Standards for the efficiency measuring method of the electric motor using

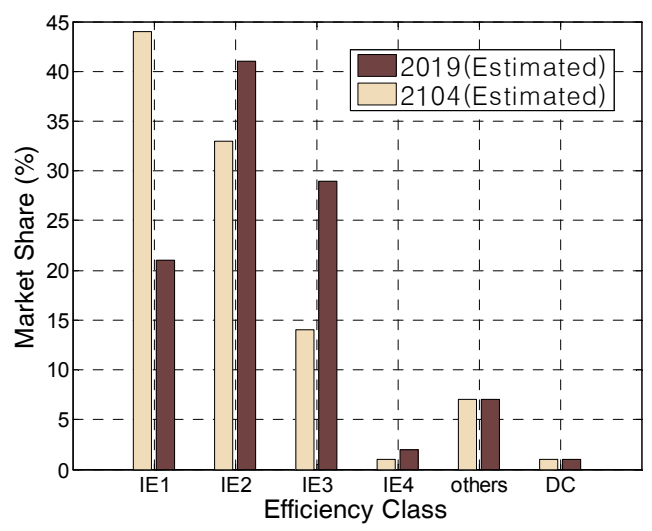

Fig. 1. Estimated low voltage motor market 2014 to 2019 
Table 2. IEC standards for the energy efficiency motors

\begin{tabular}{l|c}
\hline \multicolumn{1}{c|}{ Standard / Year of publication } & Upcoming \\
\hline $\begin{array}{l}\text { IEC 60034-2-1:2014, Edition 2.0 (2014-06-27) } \\
\text { Rotating electrical machines - Part 2-1: Standard methods } \\
\text { for determining losses and efficiency from tests (excluding } \\
\text { machines for traction vehicles) }\end{array}$ & Active \\
\hline $\begin{array}{l}\text { IEC 60034-2-2:2010, Edition 1.0 (2010-03-16) } \\
\text { Rotating electrical machines - Part 2-2: Specific methods for } \\
\text { determining separate losses of large machines from tests - }\end{array}$ & Active \\
$\begin{array}{l}\text { Supplement to IEC 60034-2-1 } \\
\text { IEC/TS 60034-2-3:2013, Edition 1.0 (2013-11-28) }\end{array}$ & A2CD* \\
$\begin{array}{l}\text { Rotating electrical machines-Part 2-3: Specific test methods } \\
\text { for determining losses and efficiency of converter-fed AC } \\
\text { induction motors }\end{array}$ & $\begin{array}{c}\text { Publication } \\
\text { IEC 60034-30-1:2014, Edition 1.0 (2014-03-06) }\end{array}$ \\
$\begin{array}{l}\text { Rotating electrical machines-Part 30-1: Efficiency classes } \\
\text { of line fed AC motors (IE code) }\end{array}$ & Active \\
\hline $\begin{array}{l}\text { IEC/TS 60034-30-2 Ed. 1.0 } \\
\text { Rotating electrical machines-Part 30-2: Efficiency classes } \\
\text { of variable speed AC motors (IE-code) }\end{array}$ & APUB \\
\hline * A2CD : Approved for 2nd Committee Draft \\
${ }^{* * *}$ APUB : Draft Approved for Publication \\
\hline
\end{tabular}

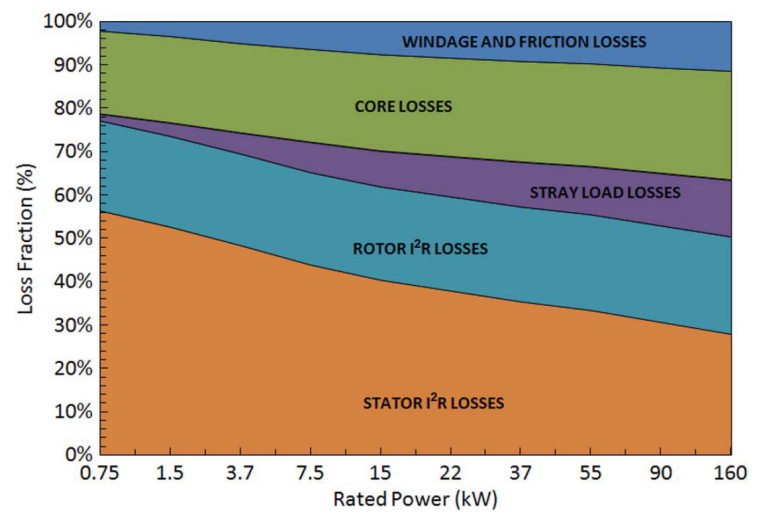

Fig. 2. Average loss fraction in SCIMs

the electric power conversion system (IEC/TS 60034-2-3) and their efficiency codes (IEC/TS 60034-30-2) are still being established. In the future, the induction motors driven by the inverter will be included in the MEPS (Minimum Energy Performance Standard). The next few years will become a critical time for the motor manufacturers.

Loss of the motor is significant in the order of stator copper loss, core loss, rotor copper loss, stary load loss, and windage loss. Fig. 2 shows the ratio of various losses of a typical induction motor [3]. Among them, the rotor copper loss is one of the features that can be found in the induction motor. Rotor copper loss reduction is required in order to raise the efficiency of the induction motor. For this, many studies have been conducted on the cage bars produced using copper, of which the electrical conductivity is higher than that of aluminum. However, copper diecasting still has problems to solve in order for the technology to be commercialized. Therefore, the production of IE5 grade induction motor is still expected to be difficult at present. Table 3 shows the prediction of the possibility to achieve the expected efficiency in the IEC60034-2-1:2014.
Table 3. Energy efficiency potential of motors

\begin{tabular}{c|c|c|c}
\hline & IE3 & IE4 & IE5 \\
\hline 3ph induction motor & $\bigcirc$ & $\triangle$ & $\times$ \\
\hline 1ph induction motor & $\bigcirc$ & $\triangle$ & $\times$ \\
\hline Line fed synchronous motor & $\bigcirc$ & $\triangle$ & $\times$ \\
\hline
\end{tabular}

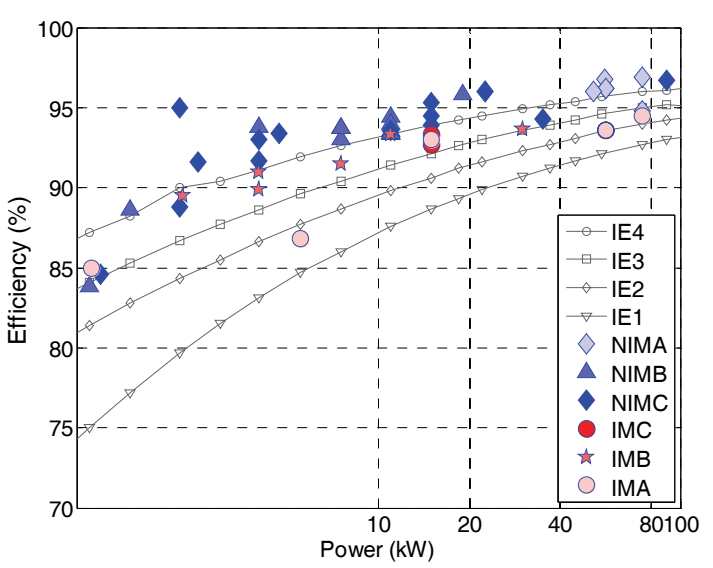

Fig. 3. Efficiency limits of 50Hz, 4poles IM and Efficiency of motor samples

It is expected to be difficult to achieve IE5, even for the line fed permanent magnet motors.

Fig. 3 shows the efficiency of the motors taken from the IEEE paper published on the subject of high-efficiency motors during the last 10 years. Legend IMA, IMB, IMC refer to the induction motor, and NIMA, NIMB, NIMC are motor other than the induction motor. Legend A denotes the motor efficiency taken from the papers during 2006 2009, B between 2010 2012, and C between 2013 2016. At present, production of induction motor efficiency levels above IE4 seems challenging. However, permanent magnet type motor has already reached the IE5 level of efficiency, and many researches has been taken place on the electric motor of the IE5 class in recent years. Looking at recent trends, one naturally see that the attention of the motor industry is focused on the development of the motor using a permanent magnet.

\section{Classification of High-efficiency Motors}

The recent research trends generally classify highefficiency electric motor into different categories based on two different criteria.

The first criterion is based on the use the drive power converter (inverter) for the motor. So far, most industrial motors are the induction motor which is driven at a fixed speed without a power conversion device. Therefore, the MEPS is also focused on the three-phase induction motor. Recently, however, there have been many papers published that are related to the efficiency improvement and measurement of inverter-fed motors. Since 2013, the Standard 


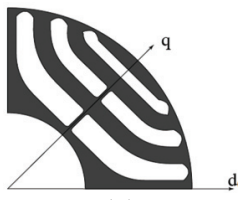

(a)

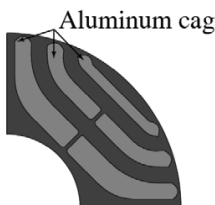

(b)

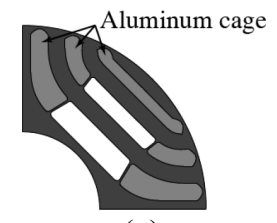

(c)
Fig. 4. Cross section of Line Start SynRM $(b, c)$

IEC / TS 60034-2-3, that is related to measuring the efficiency of an induction motor or a permanent magnettype motor driven by the inverter, is currently on the process of becoming enacted.

The second criterion is based on the use of the permanent magnet. Loss of the induction motor is accounted for approximately $15 \%$ of the loss in the rotor windings, as shown in Fig. 2. Therefore, the attention in the industry has been shifted to the permanent magnet type motor of which the rotor windings were replaced by permanent magnets in order to improve efficiency. Depending on the method of application of a permanent magnet, it may be classified in PMA-SynRM, SPM, IPM, etc.

\subsection{Classification according to whether the inverter uses}

Varying the speed drive is the fundamental role of the inverter in a typical electric motor. The inverter may adjust the output based on the load, and it is also able to drive the variable speed. When the induction motor is operated at a fixed speed in a particular situation, such as in a pump system, the efficiency of the motor may decline significantly. In such a case, using inverter-fed motors may save much energy. [4] On the other hand, the efficiency of line fed motors may fluctuate when the load changes because of the changes in the speed and the slip of the motor. However, there is an economic benefit of using such motor because a power conversion device is not needed.

\subsubsection{Line fed motors}

When considering the replacement of the industrial 3phase induction motor with the synchronous machine to increase the motor efficiency, accompanying additional cost must be considered. It's difficult to replace an electric power conversion system because of its high cost. Therefore, significant demand in the market is expected for the line fed permanent magnet motors which do not require power conversion devices. Assuming that there is no loss in the rotor windings of the induction motor at synchronous speed, the efficiency of line-fed motors is expected to exceed IE4. [5] If additional reduction of the iron loss is possible, it is expected to be a good alternative to the class IE4 low-power electric motors, in particular. The line-fed motor can be classified in the form of SPM, IPM, PMa-SynRM and SynRM based on the amount of the permanent magnet in the motor. SPM/IPM is advantageous in terms of efficiency because of high amount of the permanent magnet. In terms of cost, a SynRM type which does not use a permanent magnet is advantageous.

Studies on line fed SPM/IPM have been carried out steadily in recent years. [6, 7] Meanwhile, due to the recent rise in price of the permanent magnets, many studies have been made also for a line-fed SynRM. As shown in Fig. 4, one study achieved a more efficient class IE4 by inserting aluminum in the barrier of SynRM. [8] This method may be a good alternative to the IE4 motors to reduce the use permanent magnets. However, these line-fed motors have common problems such as unstable starting or un-synchronization. For commercialization, these problems must be considered, and many researches regarding these problems are taking place at present.

\subsubsection{Inverter fed motors}

The inverter drive also enables smooth start and stop for the motor. Therefore, the rate of failure may be decreased by reducing the mechanical impact. In addition, by controlling the speed, torque, and other mechanical properties, the inverter drive can optimize the process and enhance the productivity. Furthermore, it is advantageous in that an efficient operation is possible because the power factor can be set high for the partial load. However, it requires additional sensors, such as encoder or resolver, which results in additional costs. Moreover, considering the efficiency of a power conversion device in the system efficiency, overall system efficiency may be lower than that of the line-fed motors. Accordingly, the combination of high efficient permanent magnet motor and inverter does not have advantages over line-fed 3 ph high efficient induction in the case of a fixed speed drive.

\subsection{Classification according to whether PM uses}

\subsubsection{Non-PM motors}

Synchronous motor that does not use a permanent magnet may be considered SRM and SynRM. However, SRM is difficult to use in industrial applications, because it has inherent vibration issues and also because it requires unique inverter structure. On the other hand, the stator structure and the power converter of SynRM are same as those of the induction motor. Since you only need to change the rotor from an induction motor, it is advantageous to consider commercialization for the SynRM. In addition, because permanent magnet is not used, magnetizing process and demagnetization of the permanent magnet do not need to be considered, and it has robust structure like as an induction motor. Thus, many studies have been conducted recently regarding the use of the SynRM. [9, 10] However, the electric power conversion system must be required to drive, and thus system efficiency is lowered. It is a disadvantage in terms of efficiency compared to the PMSM. 


\subsubsection{PM motors}

Permanent magnets are mainly classified into ferrite, alnico, samarium-cobalt and neodymium series. Neodymium or ferrite magnets are used a lot in the motor. In recent years, neodymium magnets that can be used at temperatures higher than $180{ }^{\circ} \mathrm{C}$ been developed, and their utilization has been rising. However, recently, ferrite magnets have gained interest in the industry because neodymium magnets are expensive and their prices vary greatly. Ferrite magnets also have the advantage of low eddy current losses due to high resistivity. Recently, studies on the motor using a permanent magnet is made primarily for the IPM and PMA-SynRM, which have salient structure. These motors can utilize the reluctance torque due to their salient structures, and it is possible to variety of ways for the control. Furthermore, due to their characteristics, the possibility of demagnetization is small compared to the SPM.

\section{A. PMA-SynRM}

It is clear that utilizing a permanent magnet can increase the efficiency of electric motors. However, the study to reduce the amount of the permanent magnet is active due to the rising price of the permanent magnet. SynRM is a structure without a permanent magnet, as shown in Fig. 5 (a). From SynRM, PMA-SynRM structure can be formed with the permanent magnets inserted into the barrier. With the addition of the permanent magnet, the power factor and the efficiency can be improved. [11]

\section{B. IPM}

In compliance with the standard for a frame size, the amount of permanent magnet in the motor rises in order to increase the efficiency. Therefore, as for the IPM, there are more studies on the control method rather than on the reduction of the amount of a permanent magnet. One of the methods to effectively replace the conventional induction motor in the company is to change only the squirrel cage rotor with the permanent magnet rotor. These studies have been progressing steadily in recent years. [12]

\section{Advanced Research on IE5 Class}

Realistic alternative to meet the IE5 may be found in a form of the converter-fed motor.

In a real world application, Company WEG's 30kW permanent magnet motor weighs $76 \mathrm{~kg}$ with reduction of $71 \%$ compared with the $265 \mathrm{~kg}$ of a typical induction motor, meaning that frame size can be reduced rather significantly. [13] This margin of size means that a permanent magnet motor can become a good alternative for IE5 class motor. Some companies have already commercialized IE5 class permanent magnet motor.

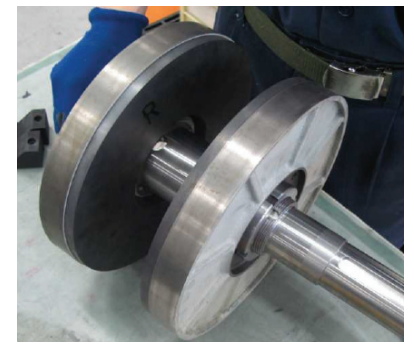

(a) PM rotor

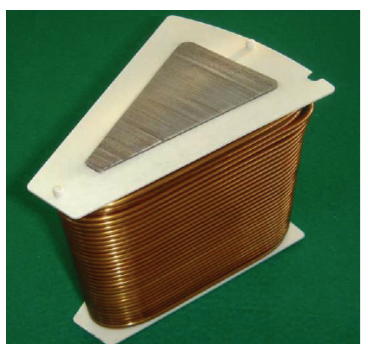

(b) Amorphous stators
Fig. 5. Axial flux permanent motor with amorphous laminated core

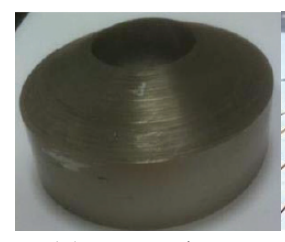

(a)Amorphous core

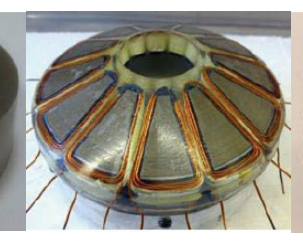

(b)Amorphous stators

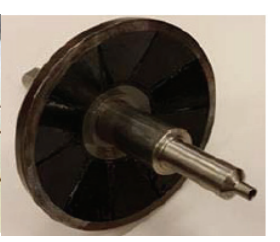

(c) $\mathrm{PM}$ rotor
Fig. 6. Rotor with PM and Amorphous stator

Another case, as shown in Fig. 5, is the IE5 level efficiency of an $11 \mathrm{~kW}$ axial flux permanent motor with ferrite magnets and amorphous laminated stator core, developed by Hitachi in Japan. [14] The prototype achieved $96 \%$ efficiency at full load operation after temperature arise became stable. The general advantages of AFPM machines over RFPM machines include higher torque density, an adjustable air gap, and better heat removal. This can be seen as a good example of effective application of ferrite permanent magnets and amorphous iron core into the design of IE5 class motors.

At the University of Adelaide, amorphous stator core was produced using a water-jet cutting method, as shown in Fig. 6. [15] Unlike Hitachi, It designed as single-sided motor and designed in the form of tapper to increase the utilization of permanent magnets.

\section{More energy saving}

If Replacing low efficiency motors with high efficiency ones requires careful analysis of the actual economic effect, but it is difficult to find such case studies in Korea.

From the studies outside of Korea, life cycle economic effect of low power motor under a few $\mathrm{kW}$ appeared relatively high compared to that of large power motor, and with uses of more than 2,000 hours per year, the economic effect was higher. [16]

Although the efficiency of the motor is an important factor in order to save energy, it is just one of the elements that make up the entire system. As an example, in the case of the pump system which accounts for large part of the total electric energy consumption, the efficiency of the 


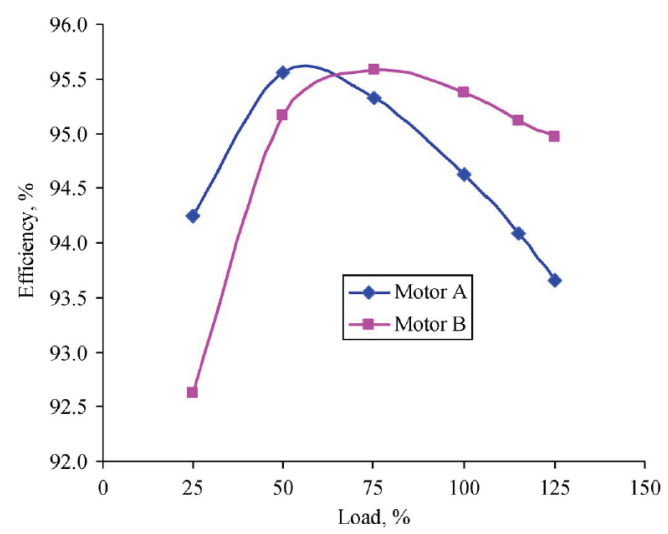

Fig. 7. Efficiency of two 75hp motors

pump itself is expected to be about 30 to $85 \%$, the motor is about 85 to $95 \%$, and flow control is about 20 to $98 \%$. [17]

Therefore, the overall system efficiency can appear in a wide range, as low as $5 \%$ and as high as $80 \%$. The efficiency of the motor is already quite high, and any further increase in efficiency is expected to be limited. On the other hand, the efficiency of the flow control can be very low at certain conditions, so more focus on increasing such inefficiency may be required to increase the overall efficiency.

Currently, the MEPS has focused on efficiency during the full load operation. However, looking at the previous studies, many operations with motor rotations at a fixed speed such as a fan, blower, and pumps, may incur load of $50 \%$ or less. As such, the motor efficiency in the partial load may be significantly lower than the rated efficiency. In addition, even if the electric motors of have same rated capacity, efficiency in the partial load can vary greatly, as shown in Fig. 7. [4] In this case, it is very difficult to exactly match the previous rotational speed if existing low efficiency electric motor is replaced with a high efficiency one. If the high efficiency motor replaces the existing three phase induction motor, the rotational speed is changed, and the efficiency may actually decrease. [18] The motors of NEMA standards generally have a maximum efficiency at the load of $50 \%$ to $60 \%$. [19] Therefore, it can be seen during an actual operation that the motor may be operating at a very inefficient condition. In many cases, the motor in the system may have over-specification because the electric motor are installed based on the maximum output that is used very infrequently. In such a case, the use of a variable speed drive can greatly improve efficiency. Many examples that achieved more than $30 \%$ higher energy savings can be found in power plant, paper manufacturing plant, or steel mill. [20]

\section{Reviews}

MEPS have started to come in effect during recent years. Therefore, the required grade may keep growing, as IE4 class induction motors are already available in the market. However, due to technical limitations, the development IE5 class induction motor is expected to be extremely difficult. Furthermore, according to literature review of papers published in last 10 years, ongoing researches on high efficiency motor are mainly focused to the permanent magnet motor. Therefore, in order to satisfy the class of IE5, a review of the permanent magnet motor is essential. In this paper, major international technologies needed to develop an IE5 class motor were reviewed through case studies. In particular, an electric motor that can replace three-phase induction motor was examined with emphasis. The pros and cons of the use of permanent magnet motors and inverters were examined, and some cases of the electric motor to obtain the maximum efficiency were listed. In addition, from the viewpoint of energy saving, the studies of the system efficiency have been reviewed.

At present, this paper covers some VSD fed motors in the 60034-30-2 and IEC 60034-2-3. However, the standards must be improved in the measuring method of efficiency and the grade of efficiency in a specific speed. In case of partial load or variable speed drive, the preparation is still weak. The efficiency difference of IE5 and IE4 is about 1 $2 \%$, and the overall motor efficiency has already reached the saturation. On the other hand, when using the VSD, the width of the efficiency of the system is left more than several tens of $\%$ p depending on the application. In order to save the energy, the more attention into this field to increase the overall system efficiency is required.

In addition to the study of the basic components of the motor, other various studies have been made such as bearings, cooling fans, case, insulation materials, manufacturing processes, cutting, dowel, magnetization, etc. For IE5 class motor development, more researches must be conducted regarding aforementioned components.

\section{References}

[1] Chausovsky, A, "IHS: Motor market update," in Conference proceedings of Motor Summit, 2014.

[2] IEC website : http://www.iec.ch

[3] A. de Almeida, F. J. T. E. Ferreira, and J. Fong, "Standards for efficiency of electric motors," IEEE Transactions on Industrial Applications, vol. 17, no. 1, pp. 12-19, 2011.

[4] IEC 60034-2-3:2013, "Rotating electrical machines Part 2-3: Specific test methods for determining losses and efficiency of converter-fed AC induction motors"

[5] de Almeida, Anibal T., Fernando JTE Ferreira, and Joao AC Fong. "Standards for Super-Premium Efficiency class for electric motors," IEEE Industrial \& Commercial Power Systems Technical Conference, 2009.

[6] Schirmer, Hans-Georg, and Gerhard Huth. "Lowpower motors in PM line-start technique with surface- 
mounted magnets," Proceedings of. VDE, 2015.

[7] Melfi, Michael J., Stephen D. Umans, and Judith E. Atem. "Viability of Highly Efficient Multi-Horsepower Line-Start Permanent-Magnet Motors," IEEE Transactions on Industry Applications, vol. 51, no. 1, pp. 120-128, 2015.

[8] Gamba, M., et al. "Line-start synchronous reluctance motors: Design guidelines and testing via active inertia emulation," IEEE Energy Conversion Congress and Exposition (ECCE), 2015.

[9] Brown, Geoff. "Developing synchronous reluctance motors for variable speed operation," IET Conference Proceedings of the Institution of Engineering \& Technology, 2012.

[10] Spargo, Christopher M., et al. "Design and Validation of a Synchronous Reluctance Motor With Single Tooth Windings," IEEE Transactions on Energy Conversion, vol. 30, no. 2, pp. 795-805, 2015.

[11] Castagnini, A., et al. "Efficiency and regulations: PM-assisted synchronous reluctance motors as a sustainable industrial solution," IEEE Workshop on Electrical Machines Design, Control and Diagnosis (WEMDCD), pp. 72-78, 2015.

[12] Ni, Ronggang, et al. "Efficiency Enhancement of General AC Drive System by Remanufacturing Induction Motor With Interior Permanent-Magnet Rotor," IEEE Transactions on Industrial Electronics, vol .63, no. 2, pp. 808-820, 2016.

[13] WEG, w22 magnet drive system 50020762 brochure

[14] Z. Wang, Y. Enomoto,, et al. "Development of IE5 High Efficiency Motor with Iron-base Amorphous Magnetic Cores," 9th International Conference on Energy Efficiency in Motor Driven Systems, pp.180190, 2015.

[15] Ertugrul, Nesimi, et al. "A Novel Tapered Rotating Electrical Machine Topology Utilizing Cut Amorphous Magnetic Material," IEEE Transactions on Magnetics, vol. 51, no. 7, pp. 1-6, 2015.

[16] de Almeida, Anibal T., et al. "Electric motor standards, ecodesign and global market transformation," IEEE Industrial and Commercial Power Systems Technical Conference, 2008.

[17] "Evaluation of energy conservation measures for wastewater treatment facilities," US Environmental Protection Agency, 2010.

[18] Emmanuel B. Agamloh, "The Partial-Load Efficiency of Induction Motors," IEEE Transactions on Industrial Applicatons, vol. 45, no. 1, pp. 332-340, 2009.

[19] Rolf Tieben, Rita Werle, Conrad U. Brunner "EASYLessons learned from four years of the Swiss EASY audit and incentive program," 9th International Conference on Energy Efficiency in Motor Driven Systems, pp. 56-63, 2015.

[20] Steyn, Fanie. "Motors and drives for improving energy efficiency," IEEE Energy Effciency Convention (SAEEC 2011), 2011.

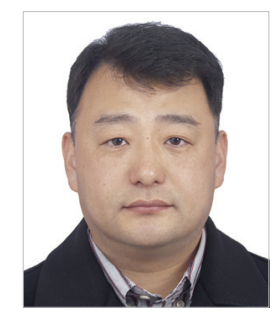

Kibong Jang He received Phd. degree in electrical engineering from Hanyang University. His research interests are analysis and drive of electric machines 